\title{
Asynchronous Learning Networks for Knowledge Workforce Learning
}

\author{
Richard H. Lytle, \\ Director, Oregon Master of Software Engineering \\ Oregon College of Engineering \& Computer Science \\ Oregon University System \\ CAPITAL Center, Room 1313 \\ 18640 NW Walker Road \\ Beaverton, OR 97006-1975 \\ Office Phone: (503) 725-2901 \\ Office FAX: (503) 725-2910 \\ E-mail: lytler@capital.ous.edu
}

\begin{abstract}
Improved workforce learning is imperative for individual knowledge workers, for companies that depend on knowledge workers, and for the U.S. economy. Meeting this need requires innovative, restructured education and training organizations; integrated knowledge drawn from currently isolated sources; and widespread replacement of the traditional classroom with appropriate learning delivery technologies. In this concept paper, a powerful and holistic solution to workforce learning is proposed, called Learning Systems Integration (LSI). While similar to current U.S. corporate and military training as a process, LSI will be significantly different in practice because it will target knowledge workers, integrate knowledge from many sources, and utilize asynchronous technology as an essential component of learning. This paper concludes with an assessment of the prospects for improved knowledge workforce learning.
\end{abstract}

\section{KEY WORDS}

ALN, Knowledge workers, Knowledge management, Higher education, Corporate training

\section{NEED FOR IMPROVED KNOWLEDGE WORKFORCE LEARNING}

As the global economy expands and becomes more knowledge-based, the demand for knowledge workers increases. In fact, the knowledge worker supply is beginning to limit economic growth in some regions of the world, including the United States. For corporations, acquiring and supporting knowledge workers is becoming the most critical factor for success. For the individual knowledge worker, the result is both enhanced career opportunity and increased pressure to learn more while working at an ever-faster pace. Knowledge workers are having great difficulty fitting learning into their professional and personal lives.

Today's approaches to knowledge workforce learning fall very short of meeting this challenge, for both companies and their workforces. These deficiencies in knowledge workforce education and training are difficult to document. For the purposes of this concept paper, they are an assumption based on personal experience with corporate managers, consultants, and members of corporate boards. These are the issues:

- The workforce being trained today will not be armed with the right knowledge for tomorrow.

- Organizations do not have a long- or short-term learning strategy based in short- and longterm business strategy.

- A different, broader set of problem-solving skills will be necessary to compete in the global marketplace. 
- The education and training industries are too often disconnected from workplace needsselling generic, fixed-price commodities that do not address industry segment or organizational requirements.

- Disconnected islands of knowledge existing in universities, training providers, and industry segment or organization-specific sources are not being integrated to meet learning demands.

- Delivery processes are modeled on the university classroom - a formal, face-to-face model that often is not well suited to workplace learning needs.

- In-house training staffs are poorly positioned to leverage different kinds of knowledge and new kinds of learning delivery.

- Many organizations are paying too much for the wrong kind of learning.

The response to this challenge is an integrative approach-integrating content from many sources, extracting new knowledge from work, and bringing learning to the workplace via appropriate information technologies. The learning process must become both efficient and closely integrated with work. Efficiency includes both reduced total costs for the corporation, and a better fit with individual work and personal lives. In this concept paper, the response is a powerful and holistic solution to workforce that is called Learning Systems Integration (LSI). As a process, LSI is similar to systems approaches to training that have been advocated for many years. These principles have been widely promoted by training companies and corporate internal training services under various names. A useful starting point for this arena is Robert M. Gagne [1]. The U.S. military has very extensive documentation to guide the process of defining and implementing training [2], [3]. My ideas for the LSI process are most closely related to information and software systems engineering. All of the foregoing approaches ultimately derive from the principles of generic systems engineering, for which a considerable literature exists.

Section II of this paper describes the LSI process. Section III deals with learning content issues. Section IV presents Asynchronous Learning Networks as the pivotal technology to implement corporate and workforce learning. Finally, Section V looks at next steps.

\section{RESPONSE TO THE NEED: LEARNING SYSTEMS INTEGRATION}

The LSI approach moves from broad industry knowledge requirements to verification of learning results as indicated by Figure 1:

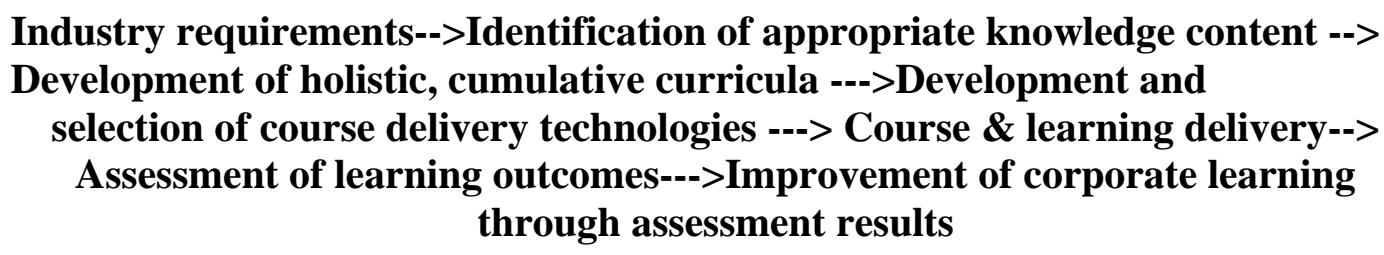

Figure 1. Learning Systems Integration Approach.

LSI is implemented in a four-stage process:

1. Scoping

2. Learning Requirements and Strategies.

3. Learning Configuration.

4. Ongoing Management and Assessment. 
Although the LSI process is usefully described in four steps, in fact the boundaries between engagements are fluid, and feedback to previous steps is extensive. These stages are described in some detail below to demonstrate the breadth and depth of the LSI approach to learning.

\section{A. Scoping}

LSI directly engages the CEO in recognizing the need to address learning in his/her company, and keeps the CEO involved at an appropriate level as the engagements proceed. The initial or sales session with the CEO establishes:

- Importance of learning for the future of the company

- Leadership role of the CEO in learning

- Shortcomings of current training approaches

- How to link business strategy with learning needs

- How to develop effective learning

- The importance of asynchronous access to learning

- How to determine whether learning contributes to the business

Illustration 1. The CEO of XYZ Insurance is absolutely convinced that he must promote learning to meet some very specific business challenges. As a business priority, he sees "disintermediation," or replacement of most individual life insurance sales by Web sales, as a competitive necessity. He has made substantial progress in planning for this business initiative, with the major exception of his instructional technology (IT) organization. He wants to know how to prepare his IT organization for this major business initiative. He is skeptical that training will ever be effective, but he feels he has to try something new because current methods are failing.

On the basis of the session, the CEO commits to a brief, low-cost step that:

- Targets high-visibility benefits that will be gained by improving corporate learning in support of business strategies and processes (involves both content and delivery).

- Summarizes current status of the company's learning program.

- Describes how LSI will contribute to achieving improvement.

- Prices the next step.

Illustration 2. The scoping step verifies that learning strategies in IT are not aligned with this business requirement and documents with examples. IT managers were unaware of this business priority and are eager to develop the skills required, and they want help concerning how to proceed. The scoping report lays out very generally how a range of learning will be defined to meet the need.

The CEO and the CIO commit to the second engagement.

\section{B. Learning Requirements and Strategies}

This step completes the scoping phase and develops the foundation for LSI. Specifically, this phase:

- Completes the business-learning alignment assessment.

- Derives learning requirements (content and delivery).

- Runs learning requirements against existing staff learning status to derive learning gaps. 
- Develops comprehensive, detailed learning strategy (content and delivery, sources of curriculum development, and learning delivery).

- Prices the Learning Configuration Step.

Illustration 3. Learning requirements for the IT organization's support of Web-based life insurance sales are established. The IT organization has an operational "knowledge gap" methodology that is run to identify the competencies required for this business initiative. Current staff possess many competencies, but significant gaps exist. Most important, conceptual integration across competencies is missing. For example, knowledge to bridge between the old back office systems and the new web systems through which most individual sales will be made.

Learning strategies are defined in depth, with regard to content and acquisition of knowledge. For example, a curriculum is designed that develops the concepts and set of skills required to link Web sites to back office systems. )

Also, training must be transformed from large and isolated doses to anytimelanyplace availability required for interdisciplinary teams to build the required applications._Asynchronous learning delivery combines specially developed computer based training modules with asynchronous "human" training — and transitions from training into work via asynchronous coaching where the IT staff help each other. LSI's asynchronous research and development (R\&D) staff plays a major role in course development and training of ALN teachers and coaches.

The CEO signs off on the learning strategy and the contract for setting the plan in motion, which will now be converted into a detailed learning program, ready for execution.

\section{Learning Configuration}

This step puts together the complete learning plan to implement the learning strategies laid out in the learning strategies step. More specifically, the learning configuration:

- Presents a complete learning and assessment plan, including curriculum, course content, and specified education and training partners.

- Develops courses as required especially where application of asynchronous technologies is required.

- Utilizes internal training staff as partners or replaces them with outside partners.

- Presents a contract for ongoing management and assessment.

The extent and price of this engagement depend heavily on the degree to which the required learning can be supported by existing education and training programs. If content and courses exist that can be used mostly as-is, this engagement is relatively simple in principle. However, if special curricula must be created and if many courses must be created from scratch, the configuration engagement will be complex and expensive.

At this stage, the client must sign off on learning delivery strategies as well. Commitment to anytime/anyplace or just in time learning may well involve substantial changes in the workplace.

Assessment must be concrete, achievable, and accepted by the client. A good assessment first-step is to audit each staff member's learning by auditing the asynchronous learning record.

Illustration 4. The learning configuration engagement produces a detailed contract for learning implementation that the CEO and the Chief Information Officer (CIO) approve in principle. But 
the cost of the new curriculum and the use of unfamiliar asynchronous learning technologies cause concern. The CEO requests a contract that starts with a 6-month pilot, followed by full implementation if the pilot is successful.

LSI staff and partners play a major role in supporting corporate intranet-delivered asynchronous learning. Several Sloan ALN projects are involved as partners.

In response, LSI proposes a $\$ 1 M$ pilot, delivered $90 \%$ by $A L N$, that will build the multidisciplinary IT skills needed to "connect" Web sites with back office database technologies. Assessment will be based on audit of ALN learning by individuals, and audit of the quality of coaching that ALN teams demonstrate. A successful pilot will launch a three-year, \$9M learning program.

The CEO agrees to proceed.

\section{Ongoing Management and Assessment}

In this phase, LSI manages ongoing learning activities:

- Manages delivery to meet learning requirements.

- Assesses learning as agreed upon with the client.

- Uses assessment and client reactions to improve LSI and partner services.

- Feeds back all "lessons learned" into the appropriate engagement stage.

- Feeds back "lessons learned" about application of asynchronous delivery of training to partners.

- Provides complete "one-stop shopping" for the client by managing the entire learning process.

- Secures additional contracts from this client.

LSI will own the curriculum and course content that it develops. However, it is expected that most course content will be owned by LSI partners, and that they will deliver training. LSI will contract with in-house training staff when that is in the client's best interest. Assessment will be LSI's responsibility.

Illustration 5. LSI brings together one university software engineering curriculum expert, one university HCI expert, three training organizations, and two Sloan ALN partners to deliver the pilot program. The pilot uses computer-based training combined with asynchronous teachingand extends into asynchronous coaching during the sixth month of the pilot. By reviewing computer-based training (CBT) tests and ALN records, in-house and university evaluators agree that staff are learning the skills needed to build robust connections between Web sites and back office systems to support Web-based insurance sales. Technical staff and their supervisors rate the learning and coaching system very highly. A few client staff are counseled about their lack of learning progress.

LSI and XYZ Insurance proceed with the three-year, \$5M contract. 


\section{E. Summary of Learning Systems Integration}

LSI, as its name implies, operates as a systems integrator. It drives the process, and manages the overall learning environment. For content and learning delivery, LSI relies mostly on partners-universities, training companies, and internal training organizations. LSI serves its customers by providing only the best partners in these roles.

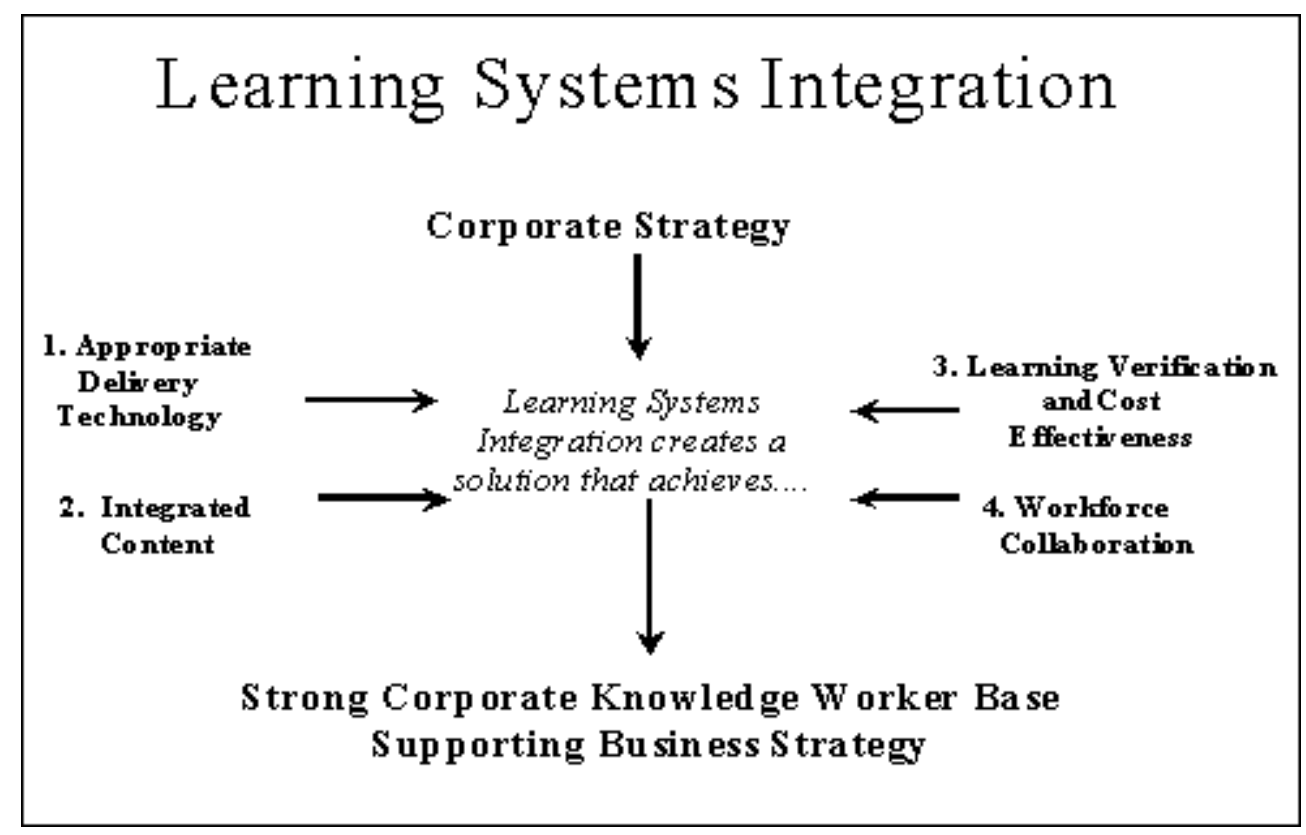

Figure 2. Scope of Learning Systems Integration

Figure 2 illustrates the scope of LSI:

In the broadest sense, corporate strategy drives learning that creates the base of knowledge workers who in turn implement the business strategy. In today's business environment, strategies and therefore learning requirements are undergoing continuous change. The LSI process integrates content, verifies learning, and supports knowledge workforce collaboration-all as facilitated by appropriate technology and content partners.

The following two sections focus on sources of knowledge, and learning delivery technologies.

\section{INTEGRATING SOURCES OF KNOWLEDGE AND LEARNING}

Until very recently, learning has been the virtual preserve of K-12 and higher education. For a number of reasons, this educational monopoly is breaking down. A brief review of the isolated islands of knowledge provides a framework for the integration needed to meet the learning needs of corporations and their knowledge workers. In this section, I am particularly indebted to the ideas of Dr. Frank Mayadas, Program Officer at the Sloan Foundation.

The four islands of knowledge can be summarized as follows:

1. Broad, structured knowledge. Provided by institutions of higher education, this knowledge may derive from the universities themselves or from other sources, but the knowledge is synthesized 
and organized via curricula developed by tenured faculty. University curricula are developed over considerable amounts of time, pass through tortuous review processes, and may be out of date by the time that they are delivered. Learners spend years earning a degree. The university degree is a very important credential-and a credential that protects the university from competition. University degrees often mean very little to corporations.

2. Industry-specific, technique or tool-focussed knowledge. For example, this is the knowledge that technicians possess concerning specialized equipment, or knowledge that computing staff have about programming languages. This island is the preserve of the generic training industry, including internal and external trainers.

3. Firm-specific knowledge. Examples include knowledge of a firm's human resources policies or knowledge about a new drug to support pharmaceutical salesmen. This knowledge falls through the cracks of most formal education/training organizations today. Universities cannot deal with it and training organizations seldom understand the business well enough to play a role.

4. Newly minted knowledge. Much new knowledge is created through industrial practice. This emerging knowledge is very closely related to a company's strategic business processes-for example, development of a new manufacturing process or a new product delivery process. This knowledge is developed in conjunction with work and is fragmented and difficult to communicate. Formalizing the knowledge for transfer to others is often problematic. This knowledge exists mostly in the minds of its creators, but it can be transferred to internal training staff for propagation. Much attention is being given to this new knowledge through the knowledge management movement. But knowledge management usually ignores learning.

These isolated islands of knowledge form barriers to the learning required by today's knowledge workers. Universities all too often assign themselves an exclusive role in "substantial" learning, and faculty may miss the opportunity to contribute to industry and firm specific knowledge, and new corporate knowledge. Industry, in turn, is dissatisfied with higher education, as exemplified by the corporate university. Generic training firms, almost polar opposites to universities, look for the most profitable "one size fits all" training that they can sell and resell, and they are generally not well regarded by industry. Internal training staff are often not well regarded, and they are usually too far removed from emerging knowledge to play a role in that key area. Corporate management generally does not know how to deal with the critical issue of learning in the corporation. The sum result is that the islands of knowledge are very difficult to integrate and focus on the learning needs of the corporate knowledge workforce. The right kind of knowledge is not available to the right people at the right time in most of today's industries. Compounding these problems is the reality that the model for learning delivery is the university classroom—a very weak model for learning and applying knowledge to work.

Going forward, better knowledge workforce learning will depend upon leadership from aggressive boundary-spanners. University professors are needed to contribute to learning that combines acquisition of market-driven skills with maintenance of a cognitive context into which these skills can be related over time. Trainers who focus on transfer of knowledge about tools and methods need to look for a wider framework from which their training will derive more value. Companies need to encourage bottom-up efforts by knowledge workers to codify new knowledge on the job in a form that will facilitate its transfer to others. Knowledge workers themselves need to manage their own knowledge bases throughout their careers. And corporate leadership must formulate, fund and execute polices that contribute to knowledge workforce learning that advances corporate strategy. 


\section{THE POWER OF ALNS FOR IMPROVING KNOWLEDGE WORKFORCE LEARNING}

Asynchronous technologies constitute the linchpin for the LSI paradigm. While "any time/ any place" remains the fundamental advantage of ALN, the ability to access and integrate learning from many sources is very important for knowledge workforce learning. Learners need to apply new skills quickly in order to retain what they have learned. In many areas of workforce learning, Technology-Based Training (TBT) is used, and ALN makes it possible to mix TBT and human delivered learning more easily, a technique that is practically impossible with traditional learning delivery methods. Also, with ALN, learning can progress seamlessly from TBT to coaching to collaboration on the job. Finally, as training progresses, knowledge from different sources-generic, industry-based and individual company-based—can be integrated.

The following scenario, in which a COBOL programmer learns Visual Basic, illustrates how ALNs play a pivotal role in LSI.

Illustration 6. A COBOL programmer with no Visual Basic experience begins by using a TBT product to learn the Visual Basic programming language. Learning entirely from a TBT is "any timel any place" learning, and it is truly self-paced. But TBTbased learning is also widely believed to encourage procrastination. So, even at this earliest stage of learning the programming language, the novice programmer needs some access to human interaction. This student is tracked on ALN by an instructor or teaching assistant, and brief exercises are added to test learning in critical areas. As the programmer gains basic command of the language, he becomes engaged more with the teacher on the ALN and less with the TBT. The learner also begins to interact with other students as well as with the instructor. The high point of this stage of learning is a practice system development project designed for the course, in which the emerging programmer has to make judgement calls about how to solve a programming problem.

Up to this point, the learning had been based on generic knowledge-knowledge that can be applied across most if not all industries. The culminating project, however, begins to deal with industry-specific applications-in this case, the financial services industry. After the conclusion of the practice project, our novice programmer is ready to start real work. While the novice programmer must take and pass certification examination, review of the ALN record of work by instructors and company competency leaders will be a better base for assessing competency. The programmer now begins work at his company site under the careful guidance of a senior programmer-a coach —located 500 miles away at another company site. For the first time, our novice programmer is "on his own." But he has a coach available on the Internet, and he can ask her questions or send her code for review. Within 18 months, our programmer has become a collaborator with other technical staff, and may eventually be designated a coach. Our programmer is now working on company specific applications-and therefore his learning is company specific. The result of his collaboration with company and consulting technical staff on the ALN is creation of new company knowledge-for example, programming solutions in support of the company's business directions, and improvement of company business processes. 
This scenario illustrates the following principles of LSI:

- Integrating learning plans with organization strategy. The programmer's learning is tied directly to basic organizational strategy and therefore to career development. The programmer's success supports the business need to adapt to a new organizational structure.

- Integrating isolated sources of knowledge. As the programmer moves through his training, the program provides both generic skill training and organization-specific knowledge.

- Integrating learning schedules with work life(delivering learning at the right time and place). The programmer uses self-paced and then asynchronous learning to provide a schedule more easily matched to the schedule of a working professional.

- Integrating human delivery with technology-based delivery. As the programmer moves through the training, he progresses from learning through technology-based delivery with modest human support to technology-supported delivery with extensive person-to-person interaction.

- Integrating teaching with coaching. In traditional classes, where learning and doing are completely separate, students often have difficulty when they try to apply what they have learned. The programmer in this scenario carries learning support with him as he moves from beginning student to proficient practitioner.

- Integrating learning with learning verification. The permanent record of ALN activity, documenting the regular interaction of the programmer with his instructor and coach, provides a very rich basis for evaluation of the programmer and effectiveness of the training. This evaluation is a key element for supporting continuous improvement of the learning process.

\section{CHALLENGES TO IMPLEMENTING ALN-BASED KNOWLEDGE WORKFORCE LEARNING}

It is far from inevitable that the power of ALNs to improve the knowledge workforce will be realized. At best, the extensive use of ALNs for workforce learning is several years in the future. At worst, the power of ALNs will never be fully realized in this arena.

To be compelling in the marketplace, LSI must be commercially produced and sold as much as possible as a common set of learning solutions across workplace environments, while implementing customized modules as company needs dictate. Cost effectiveness also implies development of a compelling cost effectiveness model that will convince corporate executives that LSI solutions are worth the cost. Substantial marketing and sales hurdles must be overcome. Industry executives are skeptical of the effectiveness of training - and for good reason. Moreover, ALNs are often counter-intuitive to executives, professional staff, and teachers and trainers.

More specifically, successful introduction of ALNs into workplace learning will require the following:

- Cost/Benefit Analysis. A convincing cost/benefit analysis for the adoption of LSI, developed in conjunction with corporate customers.

- Solution Set Definitions. An approach to leveraging a set of common learning solutions across workplace environments, while integrating customized solutions as corporate needs dictate.

- Market Niche Identification. Identification and definition of industry segments for initial widespread introduction of LSI. This provides a focus for integrating content to focus on strategic corporate needs. 
- Requirements Engineering Approach. A definition of our requirements engineering approach to aligning training with corporate needs.

- Process Improvement. Apply continuous process improvement methods to LSI.

- Technology Evaluation. Continuous evaluation of technology for improvement of learning.

- Measurable Learning Verification. A framework and particular measures of learning verification developed in conjunction with our industrial partners.

While a number of ALN projects have an industry focus, the need is for a commercially viable business model that incorporates LSI as outlined in this concept paper. Who will take the next step?

\section{REFERENCES}

1. Gagne, Robert M., Briggs, Leslie J., and Wagner, Walter W., Principles of Instructional Design, $3^{\text {rd }}$ Edition, Holt, Reinhart and Winston, Inc., ISBN0-03-011958-8, 1998.

2. Department of the Army, Field Manual 21-6, How to Prepare and Coordinate Military Training, Nov. 1975.

3. Department of the Army, Field Manual 25-100, Training the Force.

\section{ACKNOWLEDGEMENTS}

This paper draws heavily upon frequent discussions between Stephen Andriole, Frank Mayadas, Gregory Hislop and myself. I hope that I have taken full advantage of their perspectives.

\section{ABOUT THE AUTHOR}

In April 1999, Dr. Lytle became Director of the Oregon Master of Software Engineering. From 19871998, Dr. Lytle was Dean of the College of Information Science and Technology and Isaac L. Auerbach Professor of Information Systems at Drexel. From 1982 to 1987, Dr. Lytle was Director of the Office of Information Resource Management at the Smithsonian Institution, where he had responsibility for central computing, telecommunications, and information technology planning. Prior to this, Dr. Lytle established information management programs at Washington University, Rice University and the State of Illinois. Dr. Lytle has degrees from Rice University, Washington University, and the University of Maryland. Dr. Richard Lytle has extensive experience in technology-enabled distance learning. He secured grants for Drexel University from the Alfred P. Sloan Foundation; and designed and taught "anytime/anyplace" courses using asynchronous technologies. He speaks on distance learning in the U.S. and internationally. At Drexel, Dr. Lytle led the implementation of a successful distance learning version of the M.S. degree in Information Systems. 